\title{
Adopsi Teknologi Budi Daya dan Strategi Pengembangan Perkebunan Karet Rakyat di Kecamatan Teweh Tengah Kabupaten Barito Utara
}

Adoption of cultivation technology and development strategy in the management of smallholder's rubber plantation

\author{
Nurul Huda ${ }^{* 1}$, Budi Suharjo ${ }^{2}$ dan Ani Suryani ${ }^{3}$ \\ ${ }^{1}$ Dinas Kehutanan dan Perkebunan Kabupaten Barito Utara \\ Jl. Yetro Sinseng No. 13 Muara Teweh, Banjarmasin \\ ${ }^{2}$ Departemen Matematika, Fakultas Matematika dan IImu Pengetahuan Alam, Institut Pertanian Bogor \\ J. Lingkar Akademik, Kampus IPB Darmaga, Bogor 16680 \\ ${ }^{3}$ Departemen Teknologi Industri Pertanian, Fakultas Teknologi Pertanian, Institut Pertanian Bogor \\ JI. Kamper, Kampus IPB Darmaga, Bogor 16680
}

\begin{abstract}
ABSTRAK
Indonesia memiliki luas perkebunan karet terluas di dunia, namun produktivitasnya masih sangat rendah. Perkebunan karet di Indonesia sekitar $85 \%$ adalah milik rakyat, sebagian besar tingkat adopsi terhadap teknologi budidayanya masih rendah. Penelitian ini bertujuan untuk mengidentifikasi karakteristik internal dan eksternal yang sangat mempengaruhi tingkat adopsi petani terhadap teknologi budi daya karet, serta menghasilkan rumusan strategi pengembangan pengelolaan perkebunan karet rakyat di Kecamatan Teweh Tengah Kabupaten Barito Utara. Pengolahan dan analisis data dilakukan dengan analisis statistika secara deskriptif dan inferensia dengan menggunakan tabel distribusi persentase, analisis statistik Khi-kuadrat, analisis korespondensi dan analisis logit. Secara deskriptif tingkat adopsi petani karet $54 \%$ rendah, $40 \%$ sedang dan $6 \%$ tinggi. Uji khi-kuadrat memperlihatkan adanya keterkaitan antara tingkat adopsi dengan Jenis kelamin, umur, kursus/pelatihan, kegiatan Mencari Informasi teknologi budi daya, Dukungan Penyuluhan, Dukungan Kelompok Tani dan Dukungan Pemerintah. Hasil analisis Logit Metode Stepwise memperlihatkan ada dua variabel karakteristik internal dan eksternal yang sangat mempengaruhi tingkat adopsi teknologi budi daya karet, yaitu Dukungan Kelompok Tani dan Kegiatan mencari Informasi Teknologi Budi Daya. Strategi pengembangan pengelolaan perkebunan karet sebaiknya berbasiskan pada penumbuhan, penguatan dan pengembangan Kelompok tani (Poktan). Adanya dukungan kelompok tani dapat menumbuhkan proses peningkatan informasi dan keterampilan bagi petani. Strategi pengembangannya meliputi Penumbuhan dan pengembangan kelembagaan, serta Peningkatan dan pengembangan informasi bagi kelompok tani.
\end{abstract}

Kata kunci: adopsi teknologi, karet alam, kelompok tani, regresi logit

\begin{abstract}
Although Indonesia has the largest rubber plantation in the world, the productivity is still very low. About $85 \%$ of the plantation belongs to the majority of farmers whose adoption level of cultivation technology is still low. This study aimed to determine the internal and external characteristics that greatly affect the level of farmers' adoption of technology in rubber cultivation to come up with the formulation of development strategy in the management of rubber plantation in Teweh Tengah Sub-district, Barito Utara regency. Processing and data analysis was done by analysis of descriptive and inferential statistics using the percentage distribution tables, Chi-square statistical analysis, correspondence analysis and logit analysis. Descriptively, the technology adoption rate of rubber farmers was categorized as $54 \%$ low, $40 \%$ moderate and $6 \%$ high. A Chi-Square test showed a correlation between the level of adoption by gender, age, course/training, Information Seeking activities of cultivation technology, Extension Support, Farmer Group Support, and Government support. The analysis result of Logit Method of Stepwise showed that there were two characteristics of internal and external variables that influenced the adoption rate of rubber cultivation technology: Support of Farmer Groups and Activities of Seeking for Cultivation Technology Information. A strategy for the development of rubber plantation Management should be based on growth, strengthening and development of farmer groups. The support of farmer groups can foster the process of increasing the information and skills for farmers. Development strategy included establishment and institutional development. improvement and development of information for farmer groups.
\end{abstract}

Key words: Logit Regression, Rubber Plantation, Technology Adoption, farmer group

\footnotetext{
$\left.{ }^{\star}\right)$ Korespondensi:

Jl. Yetro Sinseng No. 13 Muara Teweh, Banjarmasin; e-mail: masnurulhuda@yahoo.com
} 


\section{PENDAHULUAN}

Indonesia memiliki potensi cukup besar untuk menjadi produsen terbesar karet alam dunia, karena luas perkebunannya terluas di dunia, yaitu 3,4 juta Ha. Dari luasan tersebut, $85 \%$ lebih didominasi oleh perkebunan rakyat, kurang dari $7 \%$ dikuasai oleh BUMN dan $8 \%$ dikuasai oleh pihak swasta. Pada tahun 2007 Indonesia hanya mampu memproduksi 2,55 juta ton, sedangkan Thailand 2,97 juta ton. Pada tahun 2009, produksi karet di Indonesia mengalami penurunan cukup tajam menjadi 2,44 juta ton, sementara Thailand justru naik menjadi 3,09 juta ton, padahal luas kebun karet Thailand 2 juta Ha. Akibat rendahnya produktivitas, produksi karet alam tidak mencukupi untuk memasok kapasitas pabrik karet remah nasional yang mencapai 3,8 juta ton/tahun (Gapkindo, 2011).

Secara umum permasalahan utama dalam perkebunan karet rakyat adalah produktivitas yang rendah, hanya sekitar $610 \mathrm{~kg} / \mathrm{ha} / \mathrm{tahun}$, padahal produktivitas perkebunan besar negara atau swasta telah mencapai $1.107 \mathrm{~kg}$ dan 1.190 $\mathrm{kg} / \mathrm{ha} /$ tahun. Rendahnya produktivitas karet rakyat disebabkan oleh luasnya areal karet yang menggunakan bahan tanam (seedling) non unggul dan tanaman umumnya sudah tua atau rusak, sehingga perlu diremajakan. Upaya peremajaan oleh petani dengan menerapkan teknologi budi daya karet sesuai teknis anjuran secara swadaya berjalan relatif lambat dan tingkat keberhasilannya rendah, karena adanya berbagai kendala, antara lain terbatasnya dana, kurangnya ketersediaan informasi dan minimnya sumber daya manusia (SDM) yang handal, serta lemahnya kelembagaan finansial. Petani karet sebagai kelompok produsen karet alam terbesar di Indonesia, perlu dibantu dan dibina di dalam pengelolaan usaha perkebunan karet agar dapat memberikan nilai tambah yang baik, serta dapat bermanfaat bagi semua pihak yang terlibat dalam usaha perkebunan karet.

Kabupaten Barito Utara memiliki total luas kebun karet seluas 53.333 ha, dengan produksi 41.564 ton slab per tahun. Perkebunan karet di Kabupaten Barito Utara sebenarnya telah memenuhi syarat sebagai bahan olah karet (bokar) untuk SIR 20 dengan produktivitas karet kering $652,4-707,27 \mathrm{~kg} / \mathrm{ha} /$ tahun menurut penelitian BPTK Bogor (2004). Data tahun 2009 menunjukkan bahwa produktivitas karet kering berkisar 784$779 \mathrm{~kg} / \mathrm{ha} /$ tahun atau meningkat sekitar 10\% (Statistik Perkebunan Kabupaten Barito Utara, 2009). Sebagai daerah yang memiliki perkebunan karet terluas dan memiliki kontribusi cukup besar di Kalimantan Tengah, sangat disayangkan bila produktivitas rataan perkebunan karet di Kabupaten Barito Utara masih tergolong rendah. Beberapa indikasi penyebab rendahnya produktivitas perkebunan karet rakyat tidak luput dari rendahnya tingkat adopsi petani dalam mengelola kebun karetnya.
Tujuan penelitian ini (a) Mengidentifikasi karakteristik internal dan eksternal yang sangat mempengaruhi tingkat adopsi petani terhadap teknologi budi daya karet, serta (b) Menghasilkan rumusan strategi pengembangan pengelolaan perkebunan karet rakyat, khususnya di Kecamatan Teweh Tengah Kabupaten Barito Utara.

\section{METODOLOGI}

Penelitian dilakukan pada lima desa di Kecamatan Teweh Tengah Kabupaten Barito Utara Provinsi Kalimantan Tengah, waktu pelaksanaan selama tiga bulan, mulai dari Bulan Juni hingga Bulan Agustus 2011.

Data primer diperoleh dari hasil pengamatan langsung (observasi), diskusi dan wawancara dengan responden petani karet dengan alat bantu kuesioner. Data sekunder diperoleh dari buku, laporan dan dokumen-dokumen lain yang terkait dengan penelitian yang diperoleh dari instansi terkait dan pustaka.

Pada penelitian ini, pengambilan contoh tahap pertama dilakukan menggunakan dengan metode contoh acak sederhana untuk menentukan wilayah Desa/kelurahan terpilih. Penarikan contoh tahap kedua dilakukan dengan metode insidental terhadap petani karet yang memiliki kebun karet dan berdomisili/tinggal menetap di wilayah Desa/ Kelurahan tersebut. Ukuran contoh yang digunakan untuk penelitian ini adalah:

$$
n=\left(\frac{Z_{\alpha / 2}}{e}\right) \quad(p(1-p))
$$

Keterangan:

$\mathrm{n}=$ ukuran contoh

$\mathrm{Z}$ = nilai pada tabel $\mathrm{Z}$

$\alpha=$ tingkat kesalahan

$\mathrm{p}=$ proposi

$\mathrm{e}=$ kelonggaran ketidaktelitian $=10 \%$

Analisis data dalam penelitian ini menggunakan analisis statistika deskriptif dan inferensial. Data yang diperoleh di lapangan diolah dengan memanfaatkan software Statistical Package for Social Science (SPSS) versi 13.0 for windows.

\section{Analisis Deskriptif}

Analisis deskriptif digunakan untuk memberikan gambaran umum mengenai tingkat adopsi teknologi petani karet berdasarkan berbagai karakteristik responden. Uji deskriptif dilakukan dengan serangkaian uji berikut:

\section{a. Analisis khi-kuadrat}

Uji khi-kuadrat berguna untuk menguji hubungan, atau pengaruh dua buah peubah nominal dan mengukur kuatnya hubungan peubah yang satu dengan peubah nominal lainnya.

Rumus khi-kuadrat: $\quad \chi^{2}=\left[\frac{\sum\left(f_{0}-f_{e}\right)^{2}}{f_{e}}\right]$ 
Dimana:

$\chi^{2}=$ Nilai khi-kuadrat, $\mathrm{f}_{\mathrm{e}}=$ Frekuensi yang diharapkan, $\mathrm{f}_{0}=$ Frekuensi yang diperoleh/diamati

\section{b. Koefisien Kontingensi (C)}

Koefisien Kontingensi digunakan untuk mengukur derajat hubungan, asosiasi atau dependensi dari klasifikasi-klasifikasi pada Tabel Kontingensi.

Rumus Koefisien kontingensi adalah:

$$
C=\sqrt{\frac{\chi^{2}}{\chi^{2}+n}}
$$

Dimana:

$C=$ Koefisien kontingensi, $\chi^{2}=$ Nilai Khikuadrat, $n=$ Besar contoh

\section{c. Analisis Data Korespondensi}

Analisis data korespondensi dilakukan terhadap peubah bebas yang memiliki hubungan nyata dengan tingkat adopsi petani karet berdasarkan hasil uji Khi-kuadrat.

\section{Analisis Inferensial (Regresi Logistik Biner)}

Dalam studi ini akan dilakukan analisis terhadap model regresi logistik menurut tingkat adopsi teknologi petani karet dengan tujuan melihat pengaruh sejumlah karakteristik internal dan eksternal petani karet dalam mengadopsi teknologi budi daya karet. Bentuk rumus umum adalah:

$$
L i=\ln \left(\frac{p}{1-p}\right)=\beta_{0}+\beta_{1} x_{i}+\beta_{2} x_{i}+\ldots \ldots+\beta_{21} x_{i}+\varepsilon_{i}
$$

\section{Dimana:}

$$
\begin{aligned}
& \text { Li : Model Logit } \\
& \text { p : peluang terjadinya suatu peristiwa } \\
& 1-p \text { : peluang tidak terjadinya suatu peristiwa } \\
& \beta_{i} \quad \text { : Koefisien Regresi Populasi } \\
& \varepsilon \quad \text { : galat } \\
& \mathrm{x}_{1} \text { : Jenis Kelamin } \\
& \mathrm{x}_{2} \text { : Umur petani } \\
& x_{3} \text { : Pendidikan Formal } \\
& \mathrm{x}_{4} \text { : Pendidikan non formal } \\
& x_{5} \text { : Pengalaman berusahatani karet } \\
& \mathrm{x}_{6} \text { : Penguasaan lahan usaha tani karet } \\
& \mathrm{x}_{7} \text { : Tenaga kerja dalam keluarga } \\
& x_{8} \quad \text { : Pemupukan modal usahatani karet } \\
& \mathrm{X}_{9} \text { : Pendapatan usaha tani karet } \\
& \mathrm{x}_{10} \text { : Aktifitas mencari informasi teknologi } \\
& \mathrm{x}_{11} \text { : Persepsi terhadap sifat teknologi } \\
& x_{12} \text { : Keberanian mengambil resiko } \\
& \mathrm{x}_{13} \text { : Pengetahuan petani } \\
& x_{14} \text { : Minat } \\
& \mathrm{X}_{15} \text { : Keterampilan } \\
& \mathrm{x}_{16} \text { : Dukungan penyuluhan } \\
& \mathrm{X}_{17} \text { : Dukungan kelompok tani } \\
& \mathrm{X}_{18} \text { : Dukungan Pemda } \\
& \mathrm{X}_{19} \text { : Dukungan sarana produksi } \\
& \mathrm{X}_{20} \text { : Dukungan pembiayaan } \\
& \mathrm{X}_{21} \text { : Dukungan pemasaran }
\end{aligned}
$$

Untuk mendapatkan hasil uji yang akurat $(<\mathrm{p}$ $0,05)$, maka hasil uji statistik Logit menggunakan metode Forward Stepwise.

\section{HASIL DAN PEMBAHASAN}

\section{Karakteristik Internal Petani Karet}

Dari kuesioner yang digunakan kepada petani karet, diketahui tingkat adopsi petani karet berdasarkan hasil perhitungan skor adalah: (a) Tingkat adopsi rendah $=54 \%$, (b) Tingkat adopsi sedang $=40 \%$, dan (c) Tingkat adopsi tinggi $=$ $6 \%$. Berdasarkan hasil analisis dengan Khikuadrat, didapatkan beberapa peubah yang berkaitan dengan tingkat adopsi sebagaimana tercantum pada Tabel 1 .

\section{Jenis Kelamin}

Jenis kelamin memiliki hubungan keterkaitan yang lemah terhadap tingkat adopsi teknologi budi daya petani karet. Terlihat dari hasil uji Khikuadrat dimana nilai koefisien kontingensi Jenis Kelamin $=0,232$ pada taraf significant $10 \%$ (nilai $\mathrm{p}-0,059$ ). Tabel 2 memperlihatkan persentase tingkat adopsi petani perempuan lebih mendominasi pada tingkat adopsi rendah (70\%), sedangkan pada laki-laki kecenderungan tingkat adopsinya masih lebih tinggi dari pada perempuan.

\section{Umur}

Umur memiliki hubungan keterkaitan cukup kuat terhadap tingkat adopsi teknologi budi daya pada tingkat kepercayaan $90 \%$. Hal ini terlihat dari nilai koefisien kontingensi Umur $=0,685$ pada tingkat $\alpha=10 \%$ (nilai $p-0,090$ ), yang berarti umur memiliki hubungan kaitan cukup kuat dengan tingkat adopsi teknologi budi daya petani karet.

Tabel 3 menunjukkan bahwa semakin tua umur, cenderung mengadopsi teknologi budi daya karet cenderung rendah. Hasil analisis korespondensi menunjukkan bahwa petani dengan umur 46-65 tahun cenderung mengadopsi teknologi rendah, sedangkan petani dengan umur yang lebih muda cenderung mengadopsi teknologi sedang dan tinggi (Gambar 1).

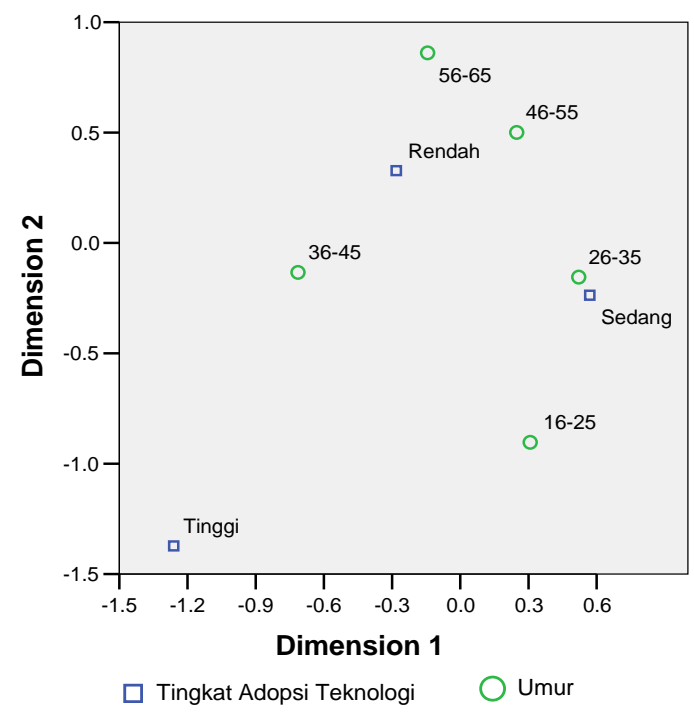

Gambar 1. Korespondensi hubungan umur dengan tingkat adopsi 
Tabel 1. Hasil uji Khi-kuadrat antara peubah karakteristik internal dengan tingkat adopsi petani

\begin{tabular}{clcc}
\hline No. & \multicolumn{1}{c}{ Karakteristik internal } & Nilai koefisien kontingensi & Signifikansi \\
\hline 1. & Jenis kelamin & 0,232 & $0,059^{\star *}$ \\
2. & Umur & 0,685 & $0,090^{* *}$ \\
3. & Pendidikan formal & 0,313 & 0,219 \\
4. & Kursus pelatihan & 0,457 & $0,000^{* * *}$ \\
5. & Pengalaman bertani karet & 0,257 & 0,313 \\
6. & Penguasaan lahan & 0,273 & 0,236 \\
7. & Jumlah tenaga kerja dalam keluarga & 0,193 & 0,692 \\
8. & Kemampuan pemupukan modal & 0,309 & 0,103 \\
9. & Pendapatan usaha & 0,188 & 0,454 \\
10. & Kegiatan mencari informasi teknologi & 0,275 & $0,086^{*}$ \\
11. & Persepsi terhadap budi daya karet & 0,406 & 0,806 \\
12. & Keberanian mengambil resiko & 0,401 & 0,260 \\
\hline \multicolumn{2}{c}{$\mathrm{N}$} & 100 & \\
\hline
\end{tabular}

${ }^{\star \star \star}$ Nyata pada taraf $\alpha=1 \%,{ }^{\star \star}$ nyata pada taraf $\alpha=5 \%$, nyata pada taraf $\alpha=10 \%$

Tabel 2. Persentase distribusi jenis kelamin menurut tingkat adopsi

\begin{tabular}{|c|c|c|c|c|c|c|c|c|c|c|c|}
\hline \multirow{3}{*}{ No. } & \multirow{3}{*}{ Jenis kelamin } & \multicolumn{6}{|c|}{ Tingkat adopsi } & \multicolumn{4}{|c|}{ Total (\%) } \\
\hline & & \multicolumn{2}{|c|}{ Rendah } & \multicolumn{2}{|c|}{ Sedang } & \multicolumn{2}{|c|}{ Tinggi } & \multirow[t]{2}{*}{$\mathrm{F}$} & \multirow[t]{2}{*}{ Rendah } & \multirow[t]{2}{*}{ Sedang } & \multirow[t]{2}{*}{ Tinggi } \\
\hline & & $f$ & $\%$ & $f$ & $\%$ & $f$ & $\%$ & & & & \\
\hline 1. & Laki-laki & 33 & 61,11 & 31 & 77,50 & 6 & 100,00 & 70 & 47,14 & 44,29 & 8,57 \\
\hline 2. & Perempuan & 21 & 38,89 & 9 & 22,50 & - & - & 30 & 70,00 & 30,00 & - \\
\hline & Jumlah & 54 & 100,00 & 40 & 100,00 & 6 & 100,00 & 100 & 54,00 & 40,00 & 6,00 \\
\hline
\end{tabular}

Sumber: Data Primer, 2011.

Tabel 3. Persentase distribusi umur terhadap tingkat adopsi

\begin{tabular}{|c|c|c|c|c|c|c|c|c|c|c|c|}
\hline \multirow{3}{*}{ No. } & \multirow{3}{*}{ Umur (tahun) } & \multicolumn{6}{|c|}{ Tingkat adopsi } & \multicolumn{4}{|c|}{ Total (\%) } \\
\hline & & \multicolumn{2}{|c|}{ Rendah } & \multicolumn{2}{|c|}{ Sedang } & \multicolumn{2}{|c|}{ Tinggi } & \multirow[t]{2}{*}{$\mathrm{F}$} & \multirow[t]{2}{*}{ Rendah } & \multirow{2}{*}{ Sedang } & \multirow[t]{2}{*}{ Tinggi } \\
\hline & & $f$ & $\%$ & $f$ & $\%$ & $f$ & $\%$ & & & & \\
\hline 1. & $16-25$ & 3 & 5,56 & 5 & 12,50 & 1 & 16,67 & 9 & 33,33 & 55,56 & 11,11 \\
\hline 2. & $26-35$ & 13 & 24,07 & 16 & 40,00 & 1 & 16,67 & 30 & 43,33 & 53,33 & 3,33 \\
\hline 3. & $36-45$ & 20 & 37,04 & 8 & 20,00 & 4 & 66,67 & 32 & 62,50 & 25,00 & 12,50 \\
\hline 4. & $46-55$ & 13 & 24,07 & 9 & 22,50 & - & - & 22 & 59,09 & 40,91 & - \\
\hline \multirow[t]{2}{*}{5.} & $56-65$ & 5 & 9,26 & 2 & 5,00 & - & - & 7 & 71,43 & 28,57 & - \\
\hline & Jumlah & 54 & 100,00 & 40 & 100.00 & 6 & 100,00 & 100 & 54,00 & 40,00 & 26.94 \\
\hline
\end{tabular}

Sumber: Data Primer, 2011.

\section{Kursus/Pelatihan}

Kursus/pelatihan memiliki hubungan keterkaitan yang kuat terhadap tingkat adopsi teknologi budi daya karet pada tingkat kepercayaan $95 \%$. Hal ini terlihat dari nilai koefisien kontingensi kursus/pelatihan $=0,457$ pada taraf nyata $\alpha=1 \%$ (nilai $p-0.000$ ). Hasil tabulasi data, persentase distribusi kursus/pelatihan dimuat pada Tabel 4. Dari Tabel 4 diketahui bahwa peningkatan jumlah kursus atau pelatihan juga menaikan persentase adopsi pada tingkat sedang dan tinggi. Hasil analisis korespondensi dimuat pada Gambar 2.

\section{Kegiatan Mencari Informasi Teknologi}

Hasil uji Khi-kuadrat kegiatan mencari informasi teknologi budi daya memiliki hubung-an lemah dengan nilai koefisien kontingensi $=0,275$ pada taraf alpha $=10 \%(p=0,086)$. Hasil tabulasi persentase distribusi kegiatan mencari iformasi teknologi budi daya tercantum pada Tabel 5 .

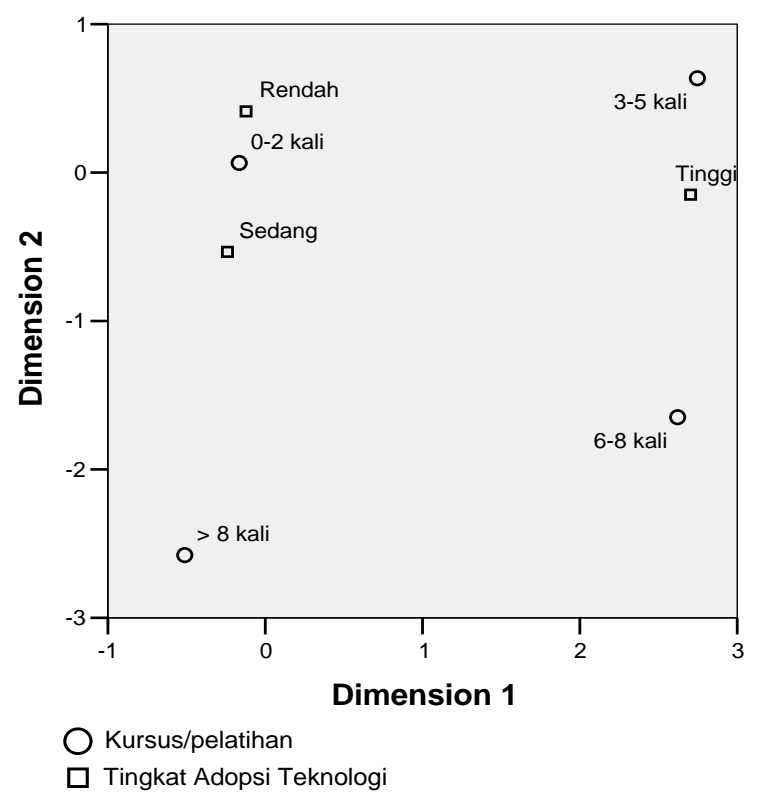

Gambar 2. Korespondensi hubungan kursus/ pelatihan dengan tingkat adopsi 
Hasil analisis korespondensi terlihat adanya kecenderungan kelompok tani yang mencari informasi budi daya karet kurang dari 3 kali tingkat adopsinya cenderung rendah, sedangkan kelompok tani yang mencari informasi lebih dari 3 kali tingkat adopsinya cenderung pada tingkat sedang dan tinggi. Hasil analisis korespondensi dimuat pada Gambar 3.

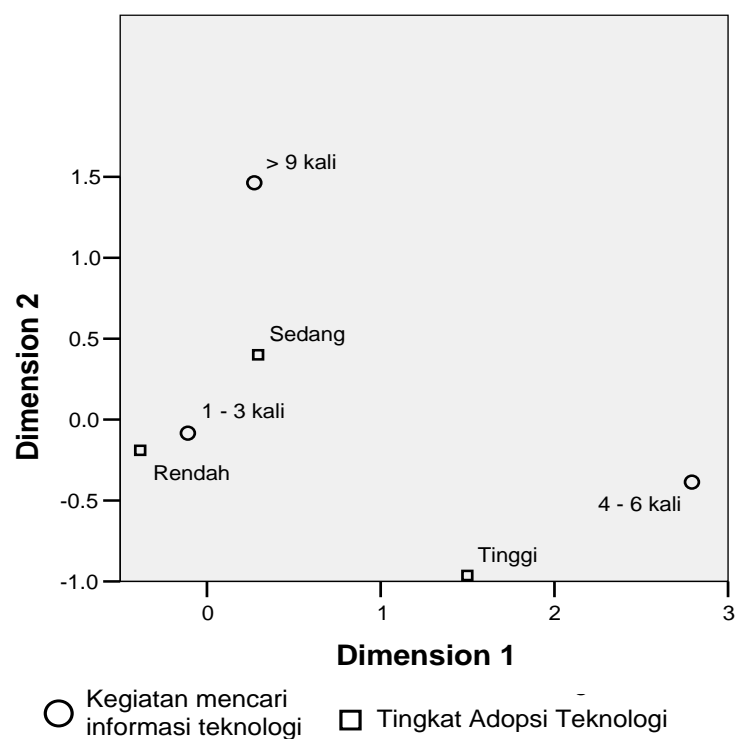

Gambar 3. Korespondensi hubungan antara tingkat adopsi dengan kegiatan mencari informasi teknologi budi daya

\section{Karakteristik Eksternal Petani}

Hasil analisis dengan Khi-kuadrat karakteristik eksternal dengan tingkat adopsi terangkum dalam Tabel 6.

\section{Dukungan Penyuluhan}

Hubungan keterkaitan antara dukungan penyuluhan terhadap tingkat adopsi teknologi budi daya karet yang kuat pada taraf kepercayaan $99 \%$ $(\alpha=1 \%)$, dengan nilai koefisien kontingensi $=$ 0,525 dengan $p$-value $(0,000)$. Hasil analisis data korespondensi menunjukkan terdapat hubungan keterkaitan tingkat adopsi dengan dukungan penyuluhan. Gambar 4 menunjukkan adanya kecenderungan, dimana dukungan penyuluhan apabila dipersepsi rendah, maka tingkat adopsi juga relatif rendah, jika persepsi dukungan penyuluhan sedang maka ada kecenderungan tingkat adopsi sedang.

\section{Dukungan Kelompok Tani}

Hubungan keterkaitan yang kuat antara Dukungan Poktan dengan Tingkat adopsi teknologi budi daya karet pada taraf kepercayaan $99 \%(\alpha=1 \%)$, dengan nilai koefisien kontingensi= 0,564 dan $p$-value $(0,008)$. Hasil analisis korespondensi (Gambar 5) menunjukkan tingkat dukungan kelompok tani memiliki hubungan keterkaitan dengan tingkat adopsi petani.

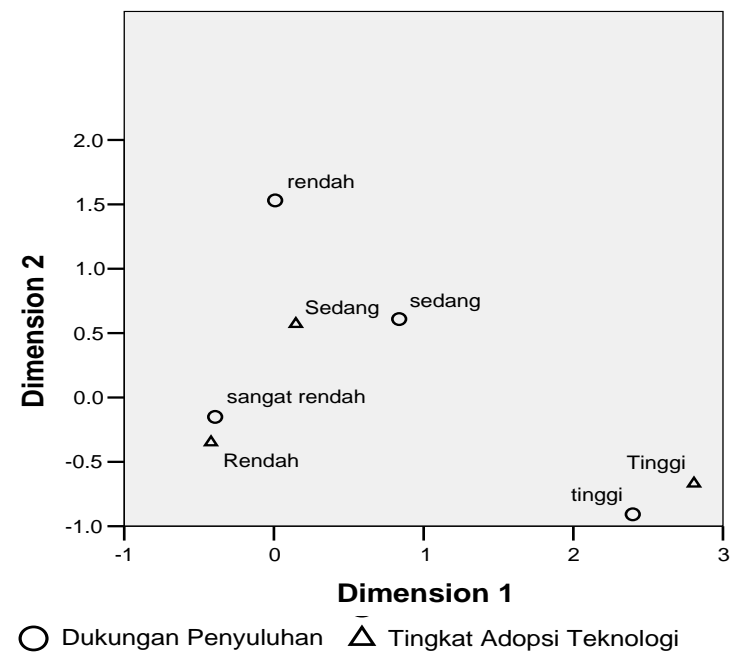

Gambar 4. Korespondensi hubungan tingkat adopsi dengan dukungan penyuluhan

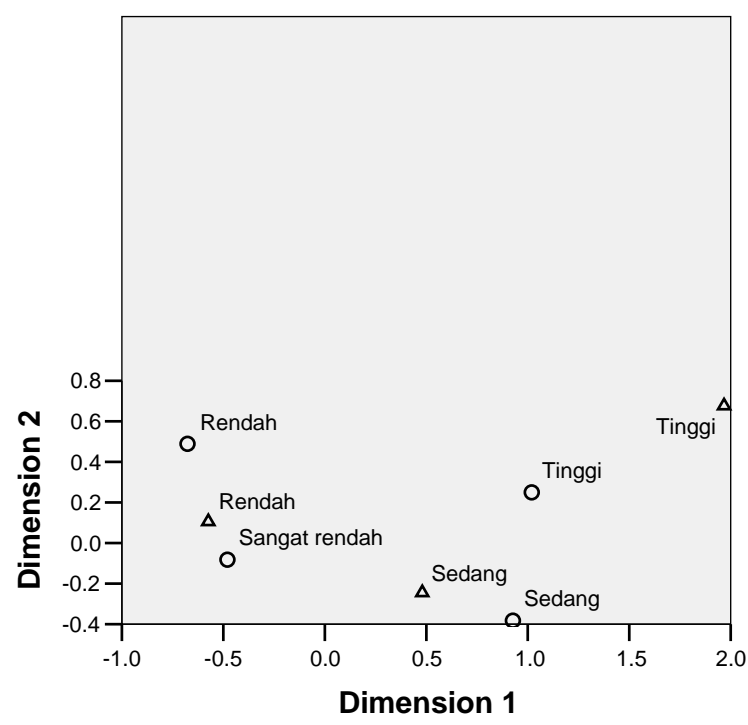

O Dukungan kelompok tani; $\Delta$ Tingkat adopsi teknologi

Gambar 5. Korespondensi hubungan dukungan kelompok tani dengan tingkat adopsi

Tabel 4. Persentase distribusi kursus/pelatihan terhadap tingkat adopsi

\begin{tabular}{|c|c|c|c|c|c|c|c|c|c|c|c|}
\hline \multirow{3}{*}{ No. } & \multirow{3}{*}{$\begin{array}{c}\text { Kursus } \\
\text { pelatihan (kali) }\end{array}$} & \multicolumn{6}{|c|}{ Tingkat adopsi } & \multicolumn{4}{|c|}{ Total (\%) } \\
\hline & & \multicolumn{2}{|c|}{ Rendah } & \multicolumn{2}{|c|}{ Sedang } & \multicolumn{2}{|c|}{ Tinggi } & \multirow{2}{*}{$\mathrm{F}$} & \multirow{2}{*}{ Rendah } & \multirow{2}{*}{ Sedang } & \multirow{2}{*}{ Tinggi } \\
\hline & & $f$ & $\%$ & $f$ & $\%$ & $f$ & $\%$ & & & & \\
\hline 1. & $0-2$ & 52 & 96,30 & 37 & 92,50 & 3 & 50,00 & 92 & 56,52 & 40,22 & 3,26 \\
\hline 2. & $3-5$ & 2 & 3,70 & - & - & 2 & 33,33 & 4 & 50,00 & - & 50,00 \\
\hline 3. & $6-8$ & - & - & 1 & 2,50 & 1 & 16,67 & 2 & - & 50,00 & 50,00 \\
\hline \multirow[t]{2}{*}{4.} & $>8$ & - & - & 2 & 5,00 & - & - & 2 & - & 100,00 & - \\
\hline & Jumlah & 54 & 100,00 & 40 & 100,00 & 6 & 100,00 & 100 & 54,00 & 40,00 & 6,00 \\
\hline
\end{tabular}

Sumber: Data Primer, 2011. 
Tabel 5. Persentase distribusi kegiatan mencari informasi teknologi budi daya terhadap tingkat adopsi

\begin{tabular}{|c|c|c|c|c|c|c|c|c|c|c|c|}
\hline \multirow{3}{*}{ No. } & \multirow{3}{*}{$\begin{array}{l}\text { Kegiatan mencari } \\
\text { informasi teknologi } \\
\text { budi daya (kali) }\end{array}$} & \multicolumn{6}{|c|}{ Tingkat adopsi } & \multicolumn{4}{|c|}{ Total (\%) } \\
\hline & & \multicolumn{2}{|c|}{ Rendah } & \multicolumn{2}{|c|}{ Sedang } & \multicolumn{2}{|c|}{ Tinggi } & \multirow[t]{2}{*}{$F$} & \multirow[t]{2}{*}{ Rendah } & \multirow[t]{2}{*}{ Sedang } & \multirow[t]{2}{*}{ Tinggi } \\
\hline & & $f$ & $\%$ & $f$ & $\%$ & $f$ & $\%$ & & & & \\
\hline 1. & $1-3$ & 52 & 96,30 & 34 & 85,00 & 5 & 83,33 & 91 & 57,14 & 37,36 & 5,49 \\
\hline 2. & $4-6$ & - & - & 2 & 5,00 & 1 & 16,67 & 3 & - & 66,67 & 33,33 \\
\hline 3. & $7-9$ & - & - & - & - & - & - & - & - & - & - \\
\hline \multirow[t]{2}{*}{4.} & $>9$ & 2 & 3,70 & 4 & 10,00 & - & - & 6 & 33,33 & 66,67 & - \\
\hline & Jumlah & 54 & 100,00 & 40 & 100,00 & 6 & 100 & 100 & 54,00 & 40,00 & 6,00 \\
\hline
\end{tabular}

Sumber: Data Primer 2011.

Tabel 6. Hasil Uji Khi-kuadrat antara peubah karakteristik eksternal petani dengan tingkat adopsi petani

\begin{tabular}{clcc}
\hline No. & \multicolumn{1}{c}{ Karakteristik eksternal } & $\begin{array}{c}\text { Nilai koefisien } \\
\text { kontingensi }\end{array}$ & Taraf nyata \\
\hline 1. & Dukungan Penyuluhan & 0,525 & $0,000^{\star \star *}$ \\
2. & Dukungan Kelompok Tani & 0,564 & $0,008^{\star \star *}$ \\
3. & Dukungan Pemerintah Daerah & 0,506 & $0,002^{* \star *}$ \\
4. & Dukungan Sarana Produksi & 0,296 & 0,293 \\
\hline
\end{tabular}

Signifikan: ${ }^{* \star *}=$ taraf alpha $1 \%,{ }^{*}=$ taraf alpha $10 \%$

Tabel 7. Persentase distribusi dukungan penyuluhan terhadap tingkat adopsi

\begin{tabular}{|c|c|c|c|c|c|c|c|c|c|c|c|}
\hline \multirow{3}{*}{ No. } & \multirow{3}{*}{$\begin{array}{l}\text { Dukungan } \\
\text { penyuluhan }\end{array}$} & \multicolumn{6}{|c|}{ Tingkat adopsi } & \multicolumn{4}{|c|}{ Total (\%) } \\
\hline & & \multicolumn{2}{|c|}{ Rendah } & \multicolumn{2}{|c|}{ Sedang } & \multicolumn{2}{|c|}{ Tinggi } & \multirow[t]{2}{*}{$\mathrm{F}$} & \multirow[t]{2}{*}{ Rendah } & \multirow[t]{2}{*}{ Sedang } & \multirow[t]{2}{*}{ Tinggi } \\
\hline & & $f$ & $\%$ & $f$ & $\%$ & $f$ & $\%$ & & & & \\
\hline \multicolumn{12}{|c|}{ Dukungan } \\
\hline 1. & Ada & 6 & 11,11 & 14 & 35 & 6 & 100 & 26 & 23,08 & 53,85 & 23,08 \\
\hline 2. & Tidak ada & 48 & 88,89 & 26 & 65 & 0 & 0 & 74 & 64,86 & 35,14 & - \\
\hline \multicolumn{12}{|c|}{ Persepsi petani terhadap dukungan penyuluhan } \\
\hline 1. & Sangat tinggi & - & - & - & - & - & - & - & - & - & 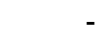 \\
\hline 2. & Tinggi & 1 & 1,85 & 2 & 5,00 & 3 & 50,00 & 6 & 16,67 & 33,33 & 50,00 \\
\hline 3. & Sedang & 4 & 7,41 & 10 & 25,00 & 3 & 50,00 & 17 & 23,53 & 58,82 & 17,65 \\
\hline 4. & Rendah & 1 & 1,85 & 3 & 7,50 & - & - & 4 & 25,00 & 75,00 & - \\
\hline \multirow[t]{2}{*}{5.} & Sangat rendah & 48 & 88,89 & 25 & 62,50 & - & - & 73 & 65,75 & 34,25 & - \\
\hline & Jumlah & 54 & 100,00 & 40 & 100,00 & 6 & 100,00 & 100 & 54,00 & 40,00 & 6,00 \\
\hline
\end{tabular}

Sumber: Data Primer, 2011.

\section{Dukungan Pemerintah}

Keterkaitan Dukungan Pemerintah terhadap tingkat adopsi teknologi budi daya karet cukup kuat pada taraf kepercayaan $99 \%(\alpha=1 \%)$, dengan nilai koefisien kontingensi $=0,506$ dan $p$ value $=0,002$ (Tabel 9). Analisis korespondensi menunjukkan keterkaitan Dukungan Pemerintah Daerah dengan Tingkat adopsi Petani (Gambar $6)$.

\section{Karakteristik petani yang paling mempengaruhi tingkat adopsi}

Analisis data diuraikan menurut model hasil pengolahan secara inferensia dengan model regresi logistik biner dengan peubah terikat berbentuk kategorik dengan pengkategorian berikut:

1. $P_{1}=P(Y=1)$ : Petani karet dengan tingkat adopsi tinggi

2. $P_{2}=P(Y=0)$ : Petani karet dengan tingkat adopsi teknologi rendah (referensi)

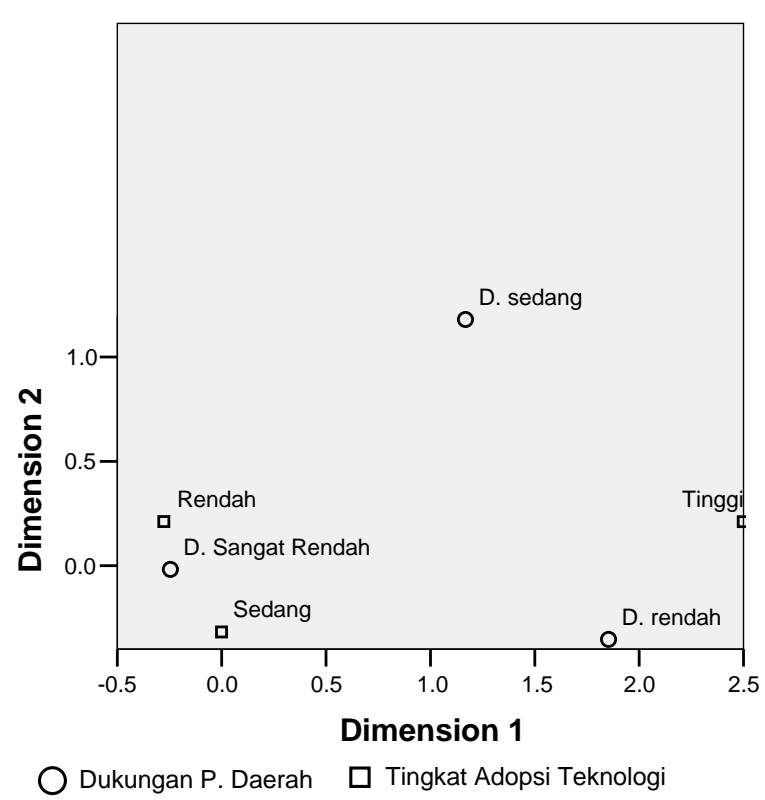

Gambar 6. Korespondensi hubungan dukungan pemerintah dengan tingkat adopsi 
Peubah bebas yang dianalisis adalah beberapa faktor yang merupakan karakteristik internal dan eksternal dari petani karet.

Pada klasifikasi tabel dapat diketahui bahwa secara keseluruhan, $75 \%$ data pengamatan dapat diprediksi secara tepat oleh model hasil estimasi. Hasil uji Logit (Metode Stepwise) menunjukkan peubah yang paling nyata mempengaruhi tingkat adopsi petani terhadap teknologi budi daya karet adalah peubah kegiatan Mencari Informasi Teknologi $\left(x_{10}\right)$ dan peubah Dukungan Kelompok Tani $\left(\mathrm{x}_{14}\right)$. Hal ini diketahui dari nilai statistik uji Wald yang mempunyai nilai nyata lebih kecil dari 0,05. Nilai uji Wald untuk Kegiatan mencari informasi teknologi adalah 4,994, dengan nilai nyata 0,025 dan nilai statistik uji Wald peubah Dukungan Kelompok tani adalah 18,364 dengan nilai nyata 0,000 (Tabel 10).

Dari hasil Tabel 10, menunjukan hanya ada dua peubah yang paling mempengaruhi tingkat adopsi petani terhadap teknologi budi daya karet, yaitu Kegiatan mencari Informasi teknologi dan Dukungan Kelompok Tani. Nilai Odds ratio = 2,034 pada kolom Exp (B) baris kegiatan mencari informasi teknologi, menunjukkan adanya peningkatan 1 satuan dalam kegiatan mencari informasi teknologi maka terdapat peluang peningkatan adopsi 2,034 kalinya. Nilai Odds ratio $=2,341$ pada kolom Exp (B) baris Dukungan Poktan, menunjukkan peluang peningkatan tingkat adopsi 2,431 kalinya setiap terjadi peningkatan dukungan Poktan dalam satuan dukungan poktan.

Berdasarkan hasil analisis logit yang telah dilakukan, maka diperoleh persamaan regresi logit sebagai berikut:

$$
\mathrm{L}_{\mathrm{i}}=\ln \left(\frac{\mathrm{p}_{\mathrm{i}}}{1-\mathrm{p}_{\mathrm{i}}}\right)=-2,741+0,710 * X_{10}+0,888 * X_{14}
$$

Keterangan:

$X_{10}=$ Kegiatan mencari informasi teknologi $X_{14}=$ Dukungan Kelompok Tani

Tabel 8. Persentase distribusi dukungan kelompok tani terhadap tingkat adopsi

\begin{tabular}{|c|c|c|c|c|c|c|c|c|c|c|c|}
\hline \multirow{3}{*}{ No. } & \multirow{3}{*}{$\begin{array}{l}\text { Dukungan } \\
\text { kelompok tani }\end{array}$} & \multicolumn{6}{|c|}{ Tingkat adopsi } & \multicolumn{4}{|c|}{ Total (\%) } \\
\hline & & \multicolumn{2}{|c|}{ Rendah } & \multicolumn{2}{|c|}{ Sedang } & \multicolumn{2}{|c|}{ Tinggi } & \multirow[t]{2}{*}{$\mathrm{F}$} & \multirow[t]{2}{*}{ Rendah } & \multirow[t]{2}{*}{ Sedang } & \multirow[t]{2}{*}{ Tinggi } \\
\hline & & $f$ & $\%$ & $f$ & $\%$ & $f$ & $\%$ & & & & \\
\hline \multicolumn{12}{|c|}{ Dukungan } \\
\hline 1. & Ada & 8 & 14,81 & 20 & 50,00 & 6 & 100,00 & 34 & 23,53 & 58,82 & 17,65 \\
\hline 2. & Tidak ada & 46 & 85,19 & 20 & 50,00 & - & - & 66 & 69,70 & 30,30 & - \\
\hline \multicolumn{12}{|c|}{ Persepsi petani terhadap dukungan kelompok tani } \\
\hline 1. & Sangat tinggi & - & - & - & - & - & - & - & - & - & - \\
\hline 2. & Tinggi & 5 & 9,26 & 12 & 30,00 & 4 & 66,67 & 21 & 57,14 & 57,14 & 19,05 \\
\hline 3. & Sedang & 3 & 5,56 & 8 & 20,00 & 2 & 33,33 & 13 & 61,54 & 61,54 & 15,38 \\
\hline 4. & Rendah & 7 & 12,96 & 2 & 5,00 & - & - & 9 & 22,22 & 22,22 & - \\
\hline \multirow[t]{2}{*}{5.} & Sangat rendah & 39 & 72,22 & 18 & 45,00 & - & - & 57 & 31,58 & 31,58 & - \\
\hline & Jumlah & 54 & 100,00 & 40 & 100,00 & 6 & 100,00 & 100 & 54,00 & 40,00 & 6,00 \\
\hline
\end{tabular}

Tabel 9. Persentase distribusi dukungan pemerintah terhadap tingkat adopsi

\begin{tabular}{|c|c|c|c|c|c|c|c|c|c|c|c|}
\hline \multirow{3}{*}{ No. } & \multirow{3}{*}{$\begin{array}{l}\text { Dukungan } \\
\text { pemerintah }\end{array}$} & \multicolumn{6}{|c|}{ Tingkat adopsi } & \multicolumn{4}{|c|}{ Total (\%) } \\
\hline & & \multicolumn{2}{|c|}{ Rendah } & \multicolumn{2}{|c|}{ Sedang } & \multicolumn{2}{|c|}{ Tinggi } & \multirow[t]{2}{*}{$\mathrm{F}$} & \multirow[t]{2}{*}{ Rendah } & \multirow[t]{2}{*}{ Sedang } & \multirow[t]{2}{*}{ Tinggi } \\
\hline & & $f$ & $\%$ & $f$ & $\%$ & $f$ & $\%$ & & & & \\
\hline \multicolumn{12}{|c|}{ Dukungan } \\
\hline 1. & Ada & 5 & 9,26 & 8 & 20,00 & 4 & 66,67 & 17 & 29,41 & 47,06 & 23,53 \\
\hline 2. & Tidak ada & 49 & 90,74 & 32 & 80,00 & 2 & 33,33 & 83 & 59,04 & 38,55 & 2,41 \\
\hline \multicolumn{12}{|c|}{ Persepsi petani terhadap dukungan kelompok tani } \\
\hline 1. & Sangat tinggi & - & - & - & - & - & - & - & - & - & - \\
\hline 2. & Tinggi & - & - & - & - & - & - & - & - & - & - \\
\hline 3. & Sedang & 2 & 3,70 & 1 & 2,50 & 1 & 16,67 & 4 & 50,00 & 25,00 & 25,00 \\
\hline 4. & Rendah & 2 & 3,70 & 4 & 10,00 & 3 & 50,00 & 9 & 22,22 & 44,44 & 33,33 \\
\hline \multirow[t]{2}{*}{5.} & Sangat rendah & 50 & 92,59 & 35 & 87,50 & 2 & 33,33 & 87 & 57,47 & 40,23 & 2,30 \\
\hline & Jumlah & 54 & 100,00 & 40 & 100,00 & 6 & 100,00 & 100 & 54,00 & 40,00 & 6,00 \\
\hline
\end{tabular}

Tabel 10. Peubah yang nyata pada model Logit (Metode Stepwise)

\begin{tabular}{llccccc}
\hline \multicolumn{1}{c}{ Parameter } & $\begin{array}{c}\text { Koefisien } \\
\text { B }\end{array}$ & S.E & Wald & $\begin{array}{c}\text { Derajat } \\
\text { bebas }\end{array}$ & $\begin{array}{c}\text { Nilai nyata } \\
\text { (p-value) }\end{array}$ & $\begin{array}{c}\text { Exp. } \\
(\mathrm{B})\end{array}$ \\
\hline - $\begin{array}{l}\text { Kegiatan mencari informasi } \\
\text { teknologi }\end{array}$ & 0,710 & 0,318 & 4,994 & 1 & 0,025 & 2,034 \\
- Dukungan kelompok tani & & & & & & \\
- & 0,888 & 0,207 & 18,364 & 1 & 0,000 & 2,431 \\
\hline
\end{tabular}




\section{Rumusan Strategi Pengembangan Pengelolaan Perkebunan Karet Rakyat}

Berdasarkan pada hasil analisis Logit dengan metode Stepwise, diketahui bahwa peubah yang paling berpengaruh terhadap tingkat adopsi petani di Kecamatan Teweh Tengah adalah peubah Kegiatan Mencari Informasi Teknologi Budi daya dan Dukungan Kelompok Tani. Dari hasil sebelumnya dengan analisis Khikuadrat beberapa peubah karakteristik internal dan eksternal yang memiliki hubungan keterkaitan dengan tingkat adopsi teknologi budi daya karet, yaitu Jenis Kelamin, Umur, Kursus/Pelatihan, Kegiatan mencari informasi teknologi, Dukungan Penyuluhan, Dukungan Poktan dan Dukungan Pemerintah.

Rumusan strategi pengembangan pengelolaan perkebunan karet rakyat untuk wilayah Kecamatan Teweh Tengah Kabupaten Barito Utara sebaiknya berfokus pada peningkatan Dukungan Poktan dan Peningkatan informasi teknologi budi daya bagi petani karet dengan tetap memperhatikan peubah-peubah lain yang terkait nyata dengan tingkat adopsi.

Strategi Pengembangan pengelolaan perkebunan karet rakyat sebaiknya berbasiskan pada penumbuhan, penguatan dan pengembangan Poktan, karena dengan adanya dukungan Poktan, maka dapat menumbuhkan proses peningkatan informasi dan keterampilan bagi petani. Strategi pengembangan pengelolaan perkebunan karet rakyat berbasiskan pada peningkatkan Dukungan Poktan adalah (1) Penumbuhan dan pengembangan kelembagaan Kelompok Tani dan (2) Peningkatan dan pengembangan informasi bagi Poktan. Kegiatan ini dapat dilakukan dengan meningkatkan peran dukungan pemerintah daerah serta dukungan penyuluhan terhadap petani, maupun Poktan.

\section{KESIMPULAN}

Adanya keterkaitan tingkat adopsi dengan karakteristik internal jenis kelamin, umur, kursus/ pelatihan, kegiatan mencari informasi teknologi telah menunjukkan bahwa peubah tersebut memiliki hubungan cukup erat untuk meningkatkan dukungan Poktan sebagai peubah yang sangat berpengaruh pada peningkatan tingkat adopsi petani terhadap teknologi budi daya. Demikian pula keterkaitan tingkat adopsi dengan karakteristik eksternal Dukungan Penyuluhan dan dukungan pemerintah daerah, memiliki hubungan erat yang mempengaruhi dan mendorong pada peningkatan dukungan Poktan sebagai proses upaya meningkatkan adopsi petani terhadap teknologi budi daya karet di Kecamatan Teweh Tengah.

Rumusan strategi pengembangan pengelolaan perkebunan hendaknya berfokus pada peningkatan Dukungan Poktan dan Kegiatan mencari informasi teknologi budi daya karet. Hal ini dapat dilakukan melalui kegiatan penumbuhan, penguatan dan pengembangan Poktan, karena bermanfaat pada proses percepatan tingkat adopsi petani terhadap teknologi budi daya karet. Strateginya yang harus dilakukan adalah (1) Penumbuhan dan pengembangan informasi bagi Poktan, serta (2) Peningkatan dan pengembangan informasi bagi Poktan. Kegiatan ini dapat dilakukan dengan meningkatkan peran dukungan pemerintah daerah serta dukungan penyuluhan terhadap petani, maupun Poktan.

\section{DAFTAR PUSTAKA}

Adam, M. 2009. Pengaruh Tingkat Penyerapan Adopsi Teknologi serta pendapatan petani Padi Sawah Pasang Surut di Kabupaten Indragiri Hilir dan Siak. Badan Penelitian dan Pengembangan Provinsi Riau. Jurnal TEROKA Vol. IX. No.02 2009.

Alam, N. 2010. Faktor-faktor yang mempengaruhi Petani Kakao dalam Adopsi Inovasi Teknologi Sistem Usaha Tani Intensifikasi Diversifikasi. Tesis. Institut Pertanian Bogor, Bogor.

Akiefnawati, R, G.Wibawa, L. Joshi dan M. Van Noordwijk. 2008. Meningkatkan produktivitas Karet Rakyat melalui sistem Wanatani: Belajar dari Bungo.

Anwar C. 2001. Manajemen dan Teknologi Budi Daya Karet. Balai Penelitian Karet Sungei Putih. Pusat Penelitian Karet, Medan.

Arifin, B. 2005. Supply-Chain of Natural Rubber in Indonesia. J. Manajemen Agribisnis Vol. 2 (1): I-16.

Cholis, M. 1998, Memacu Proses Difusi dan Adopsi Teknologi. Jurnal Sinar Tani No. 2769. Balitan Malang

Dishutbun Barito Utara. 2010. Statistik Perkebunan Kabupaten Barito Utara.

Gapkindo, 2011. Produksi Karet Alam Indonesia. http://www.gapkindo.org/ index.php/id/component/content/article/1artikel/153-perkebunan-karet-alam-id.html (3 Mei 2011).

Ginanjar, I. 2011. Modul Kuliah analisis Korespondensi. Fakultas Matematika dan IImu Pengetahuan Alam. Universitas Padjadjaran, Bandung.

Hendayana, R. 2009. Model Percepatan Adopsi Inovasi Teknologi Unggulan Badan Litbang Pertanian. Balai Pengkajian dan Pengembangan Teknologi Pertanian, Bogor

Juanda, B. 2009. Ekonometrika Permodelan dan Pendugaan. IPB Pres, Bogor.

Karsidi, R. 2007. Pemberdayaan Masyarakat Untuk Usaha Kecil dan Mikro. Jurnal Penyuluhan, Vol 3 No. 2. IPB. 
Kecamatan Teweh Tengah, 2010. Kecamatan Teweh Tengah dalam Angka Tahun 2010. Pemerintah Daerah Kabupaten Barito Utara. Muara Teweh.

Mardikanto, T. 1993. Penyuluhan Pembangunan Pertanian. Sebelas Maret University Press, Surakarta.

Nachrowi, N.D. dan Usman H. 2002. Penggunaan Teknik Ekonometri. Raja Grafindo Persada, Jakarta.

Parhusip, A.B. 2008. Potensi Karet Alam Indonesia. Economic Review. No. 213. September 2008. Jakarta

Peraturan Menteri Pertanian No. 273/Kpts/OT. 160/4/2007 tentang Pedoman Pembinaan kelompok Tani.

Rangkuti, P.A. 2009. Analisis Peran Jaringan Komunikasi Petani Dalam Adopsi Inovasi
Traktor Tangan Di Kabupaten Cianjur Jawa Barat. Jurnal Agro Ekonomi, 27(1): 45-60.

Sadono, D. 2008. Pemberdayaan Petani: Paradigma baru Penyuluhan Pertanian di Indonesia. Jurnal Penyuluhan Vol 4 No 1.

Sugiyono. 2007. Statistika Untuk Penelitian. Cetakan Duabelas (Revisi Terbaru). Alfabeta, Bandung.

Supriyadi, M. 1997. Adoption of Rubber farming technology by smallholders in two villages.Pusat Penelitian Karet Medan. Jurnal Penelitian Karet Indonesia, 15(2): 97-119.

Umar, H. 2002. Metode Riset Bisnis. PT. Gramedia, Jakarta.

Yamin, S. dan Kurniawan, H. 2009. SPSS Complete. Teknik Analisis Statistik Terlengkap dengan Software SPSS. Salemba Infotek, Jakarta. 